\title{
Endobronchial Metastasis from Adrenocortical Carcinoma
}

\author{
Kyoko Ota, Hiroaki Satoh, Shih-Yuan Lin, Junichi Fujita, Gen Ohara, Koichi Kurishima \\ and Nobuyuki Hizawa
}

\begin{abstract}
Lung parenchymal metastases are common manifestations; however, endobronchial metastasis is rare. We present herein a case of endobronchial metastasis from adrenocortical carcinoma. In the English language literature, this is the first case with such rare metastasis from adrenocortical carcinoma diagnosed antemortem. Although very rare, physicians should keep in mind the possibility of endobronchial metastasis in patients with a history of extrapulmonary malignancy including adrenocortical carcinoma.
\end{abstract}

Key words: adrenocortical carcinoma, pulmonary metastasis, endobronchial

(Inter Med 48: 1161-1164, 2009)

(DOI: 10.2169/internalmedicine.48.2113)

\section{Introduction}

Lung parenchymal metastases are common manifestations; however, endobronchial metastasis is rare. Among them, the most frequent primary tumors that metastasize to the endobronchus are breast, colorectal and renal carcinomas (1-3). Other reported malignancies include sarcomas, melanomas, plasmacytomas, ovarian, thyroid, uterine, testicular, nasopharynx and adrenocortical carcinomas (1-4). Adrenocortical carcinoma is rare and still has poor prognosis with frequent recurrence (5-9). To the best of our knowledge, only one case of endobronchial metastasis from adrenocortical carcinoma, which was diagnosed postmortem, has been reported in the English language literature (4). We report herein a case of endobronchial metastasis from adrenocortical carcinoma diagnosed antemortem and a brief review of the literature.

\section{Case Report}

A 74-year-old woman presented with a 1-month history of gradually increasing cough, dyspnea, and general fatigue. She had been diagnosed with adrenocortical carcinoma 32 months previously and had been treated with right adrenectomy. As several pulmonary metastases up to $1 \mathrm{~cm}$ in diameter in both lungs were detected on chest CT one year later, she was again treated with mitotane for 7 months. She was admitted for further evaluation of adrenocortical carcinoma. On admission, her breathing sound was decreased in the right lower lung area. A complete blood count revealed a hemoglobin value of $15.6 \mathrm{~g} / \mathrm{dL}$ and a platelet count of $201,000 / \mu \mathrm{L}$. White blood cell count was $16,900 / \mu \mathrm{L}$ and $\mathrm{C}$ reactive protein $29.87 \mathrm{mg} / \mathrm{mL}$. A chest radiograph and CT scan performed upon admission revealed an endobronchial tumor at the orifice of the left lower lobe bronchus and atelectasis with obstructive pneumonia distal to it (Fig. 1). In addition, there was pulmonary metastasis in the right lung (Fig. 2). The orifice of the right lower lobar bronchus was totally occluded by the proximal endobronchial extension of the mass. Other parenchymal pathologies, abnormal hilar or mediastinal adenopathy were not seen. Fiberoptic bronchoscopy revealed an endobronchial mass obstructing the right lower lobar bronchial lumen (Fig. 3). Bronchoscopic biopsies of the endobronchial mass were performed. The biopsy specimen was consistent with the findings of resected adrenocortical carcinoma (Fig. 4-A and B). The obstructive pneumonia was successfully treated with sultamicillin tosilate. Because of poor performance status of the patient, she received the best supportive care.

\section{Discussion}

Adrenocortical carcinoma is a rare malignant disease with a poor prognosis, and the low incidence of the disease makes it difficult to establish a standard treatment of the 


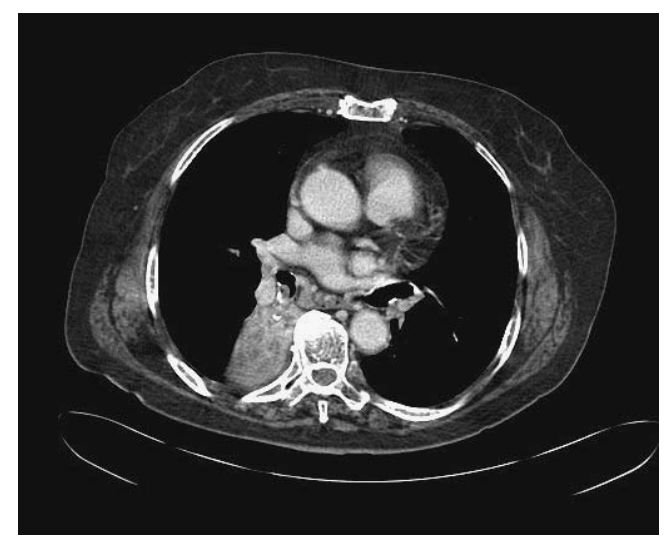

Figure 1. A contrast-enhanced CT image obtained with mediastinal window settings revealed an endobronchial tumor at the orifice of the left lower lobe bronchus and atelectasis with obstructive pneumonia distal to it.

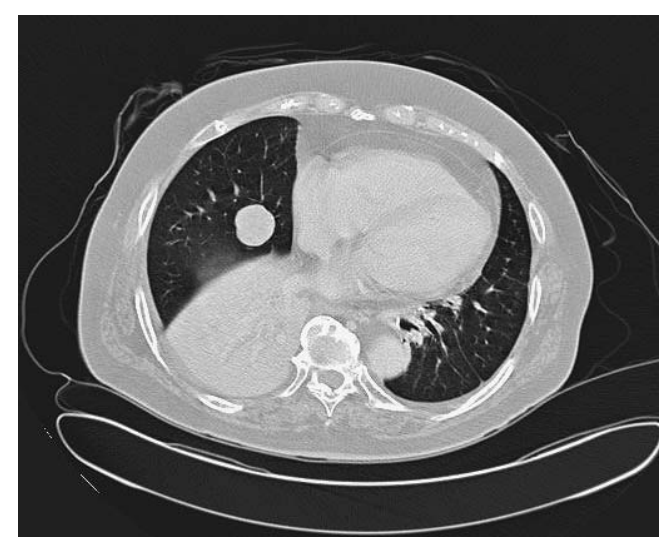

Figure 2. A chest CT scan with lung window settings showed a pulmonary metastatic lesion and atelectasis with obstructive pneumonia in the right lung.

disease (5-9). Metastatic disease to the lungs is found in the majority of patients dying of adrenocortical carcinoma (5-9), however, spread to the bronchus is very rare (4). In 1963, Trinidad et al reported 10 autopsied patients of secondary pulmonary tumors erroneously diagnosed as lung cancer (4). One of them had adrenocortical carcinoma with endobronchial metastasis (4). Thereafter, some authors referred these patients and reported that adrenocortical carcinoma was one of the common extrathoracic tumors associated with endobronchial metastasis $(10,11)$. One report in the Spanish language literature described a case with endobronchial metastasis from adrenocortical carcinoma (12). Although three cases of endobronchial metastasis from pheochromocytoma have been reported $(4,13,14)$, there have been no additional cases with endobronchial metastasis from adrenocortical carcinoma in the English language literature. In patients with endobronchial metastases, the most common symptoms are coughing and hemoptysis, with dyspnea and wheezing occurring less often $(15,16)$. In some patients, however, the metastatic lesions may be asymptomatic (17-19). The roentgenographic findings due to endobronchial metastasis are

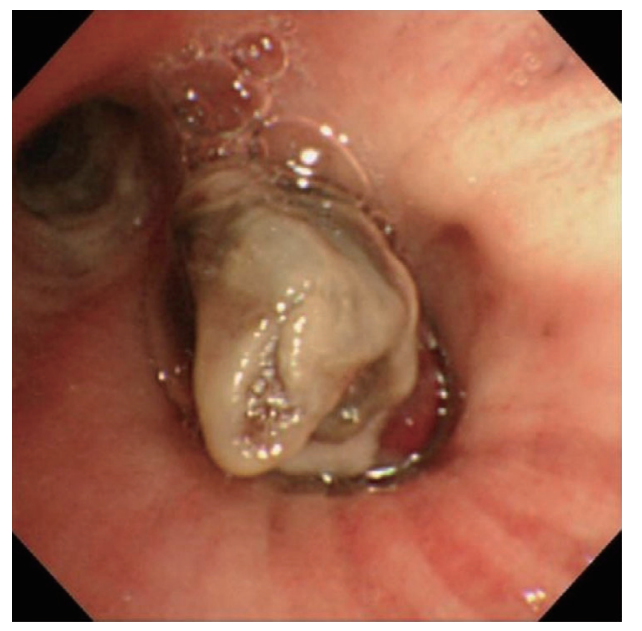

Figure 3. Flexible bronchoscopy revealed multiple small polypoid lesions in the lower bronchus of the right lung.
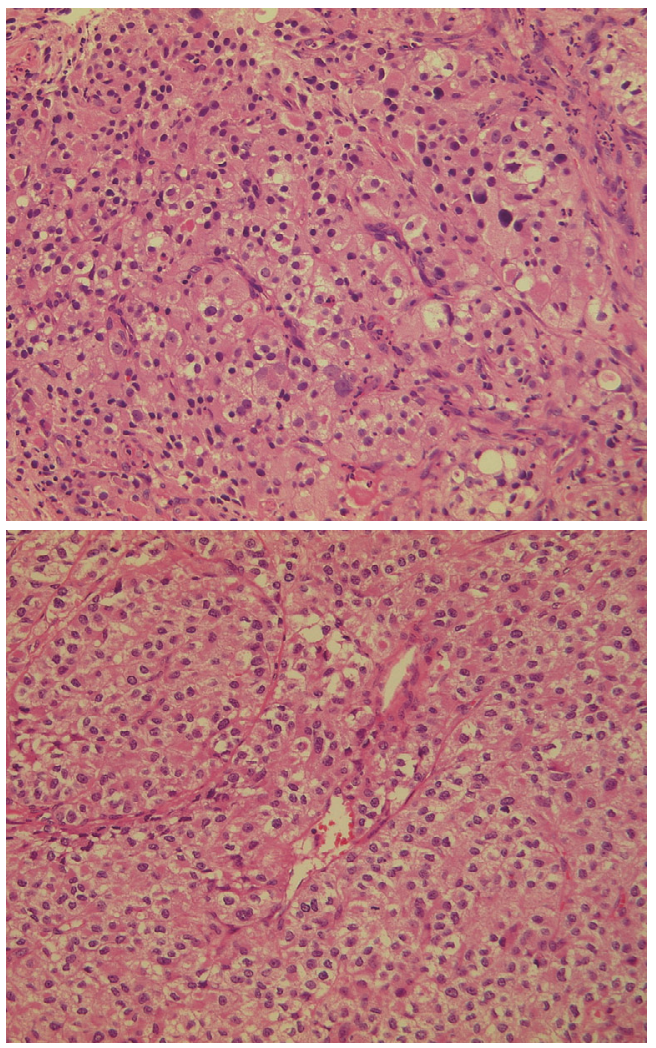

Figure 4. Histologic section of the endobronchial lesion (A). Microscopically, the tumor cell size varied and the cytoplasm was abundant, eosinophilic, and clear. Histologic section of the primary lesion (B). (Hematoxylin and Eosin staining, $\times 200$ )

considerably variable $(14,17,20)$. As shown in the present patient, lobar or segmental atelectasis, or obstructive pneumonia, is commonly observed. Pneumonic infiltration or parenchymal metastases is also encountered. Diagnosis of endobronchial metastasis can be made by bronchoscopic examination because most lesions are within the view and grasp of the bronchoscopic field. However, the value of bronchoscopic examination, in a case (10), was limited be- 
cause the admixture of necrotic material and fungal hyphae occupying the most proximal portion of the endobronchial mass interfered with the opportunity to obtain a proper diagnostic specimen. Fungal infection itself also presented as an endobronchial tumor in some cases $(21,22)$. In addition, regarding the endobronchial lesion, it is necessary to differentiate primary lung cancer from extrathoracic malignancy. The diagnosis is typically suggested by clinical evidence of an antecedent extrapulmonary primary tumor and confirmed by histologic studies of the bronchoscopic biopsy specimen. Therefore, the pathological diagnosis using specimens obtained by transbronchial biopsy is mandatory for a correct diagnosis.

The endobronchial lesion may form either by invasion from surrounding tissues such as lung parenchyma or hilar and/or mediastinal lymph nodes, or by direct seeding within the bronchial wall. Kiryu et al (18) studied the mode of metastasis in patients with endobronchial metastasis on the basis of the following four developmental conditions: type I, direct metastasis to the bronchus; type II, endobronchial invasion of parenchymal mass; type III, endobronchial invasion of mediastinal or hilar lymphadenopathy; and type IV, extension of peripheral tumor along the proximal bronchus. Akoglu et al (14) evaluated that, when Kiryu's definition (18) is used, it can be difficult to differentiate type II from type IV. Therefore they accepted all endobronchial metastasis associated with parenchymal lesion as type II. According to the Akoglu's evaluation, the endobronchial metastasis in the present patient may be type II because there was no dominant lymph node metastasis adjacent to the endobronchial metastasis. The case presented here is the second English language report concerning endobronchial metastasis from adrenocortical carcinoma. The first case was an autopsy case of secondary pulmonary tumors erroneously diagnosed as lung cancer (4). Therefore, this is the first case of endobronchial metastasis from adrenocortical carcinoma diagnosed antemortem. We did not know exactly why our case showed this extremely rare metastasis, but we speculated that the slow progression in our patient might be associated with this extremely rare metastasis. Apparently, mitotane had no direct relation to this rare metastasis, but there was a possibility that the slow progression depended on action of it. Due to the poor performance status of the patient, she received the best supportive care and she experienced symptoms of suppression. If patients have good PS, there may be a choice to perform additional systemic chemotherapy $(23,24)$ and local therapy for endobronchial metastasis (3).

The present case suggested that the adrenal gland could be a site of primary tumor of endobronchial metastasis, although it was not a common primary site. As Lee et al suggested (10), this should always be considered when investigating any endobronchial lesion, especially in patients with previous malignancies. In addition, this report confirms the importance of bronchoscopical examination in patients with a history of extrapulmonary malignancy who have endobronchial manifestations.

\section{References}

1. Salud A, Porcel JM, Rovirosa A, Bellmunt J. Endobronchial metastatic disease: analysis of 32 cases. J Surg Oncol 62: 249-252, 1996.

2. Katsimbri PP, Bamias AT, Froudarakis ME, Peponis IA, Constantopoulos SH, Pavlidis NA. Endobronchial metastases secondary to solid tumors: report of eight cases and review of the literature. Lung Cancer 28: 163-170, 2000.

3. Sørensen JB. Endobronchial metastases from extrapulmonary solid tumors. Acta Oncol 43: 73-79, 2004.

4. Trinidad S, Lisa JR, Rosenblatta MB. Bronchogenic carcinoma stimulated by metastatic tumors. Cancer 16: 1521-1529, 1963.

5. Nishida S, Itoh N, Sasao T, Masumori N, Taguchi K, Tsukamoto T. Adrenocortical carcinoma: retrospective study of 14 patients experienced at a single institution over 34 years. Int J Urol 14: 581584, 2007.

6. van Ditzhuijsen CI, van de Weijer R, Haak HR. Adrenocortical carcinoma. Neth J Med 65: 55-60, 2007.

7. Icard P, Goudet P, Charpenay C, et al. Adrenocortical carcinomas: surgical trends and results of a 253-patient series from the French Association of Endocrine Surgeons Study Group. World J Surg 25: 891-897, 2001.

8. Vassilopoulou-Sellin R, Schultz PN. Adrenocortical carcinoma. Clinical outcome at the end of the 20th century. Cancer 92: 11131121, 2001.

9. $\mathrm{Ng} \mathrm{L}$, Libertino JM. Adrenocortical carcinoma: diagnosis, evaluation and treatment. J Urol 169: 5-11, 2003.

10. Lee KY, Ryu SJ, Joo M. Endobronchial metastasis of hepatocellular carcinoma. Yonsei Med J 30: 544-547, 2003.
11. Park YB, Byun YS, Kim SK, et al. Endobronchial metastasis from stomach cancer. Respirology 4: 89-92, 1999.

12. Parajó A, Fírvida JL, Otero E, García M, Montero M. Isolated primary hyperaldosteronism caused by adrenocortical carcinoma. Arch Esp Urol 53: 931-934, 2000.

13. Sandur S, Dasgupta A, Shapiro JL, Arroliga AC, Mehta AC. Thoracic involvement with pheochromocytoma: a review. Chest 115: 511-521, 1999.

14. Akoglu S, Uçan ES, Celik G, et al. Endobronchial metastases from extrathoracic malignancies. Clin Exp Metastasis 22: 587-591, 2005.

15. Braman SS, Whitcomb ME. Endobronchial metastasis. Arch Intern Med 135: 543-547, 1975.

16. Shepherd MP. Endobronchial metastatic disease. Thorax 37: 362 365, 1982.

17. Heitmiller RF, Marasco WJ, Hruban RH, et al. Endobronchial metastasis. J Thorac Cardiovasc Surg 106: 537-542, 1993.

18. Kiryu T, Hoshi H, Matsui E, et al. Endotracheal/endobronchial metastases. Chest 119: 768-775, 2001.

19. Poe RH, Ortiz C, Israel RH, et al. Sensitivity, specificity, and predictive values of bronchoscopy in neoplasm metastatic to lung. Chest 88: 84-88, 1985.

20. Baumgartner WA, Mark JB. Metastatic malignancies from distant sites to the tracheobronchial tree. J Thorac Cardiovasc Surg 79: 499-503, 1980.

21. Husari AW, Jensen WA, Kirsch CM, et al. Pulmonary mucormycosis presenting as an endobronchial lesion. Chest 106: 1889-1891, 1994. 
Inter Med 48: 1161-1164, 2009 DOI: 10.2169/internalmedicine.48.2113

22. Magro CM, Ross P Jr. Endobronchial mimics of primary endobronchial carcinoma: a clinical study of 25 cases. Can Respir J 12: 123-127, 2005

23. Fulmer BR. Diagnosis and management of adrenal cortical carci- noma. Curr Urol Rep 8: 77-82, 2007.

24. van Ditzhuijsen CI, van de Weijer R, Haak HR. Adrenocortical carcinoma. Neth J Med 65: 55-60, 2007.

(C) 2009 The Japanese Society of Internal Medicine http://www.naika.or.jp/imindex.html 